\title{
Modification of the human blink reflex by transient and sustained features of acoustic prestimulation
}

\author{
KAREN REILLY and GEOFF HAMMOND \\ University of Western Australia, Nedlands, Western Australia
}

\begin{abstract}
The effects of acoustic stimuli whose onsets and durations were controlled to vary their transient and sustained features on the size of a subsequently elicited blink reflex were examined in humans. Prestimuli both with and without transient features inhibited the reflex when they preceded the eliciting stimulus by brief lead intervals, showing that acoustic transients are sufficient, but not necessary, for reflex inhibition. Inhibition evoked by transient and sustained stimulus features showed partial summation, and inhibition evoked by stimuli with only transient and with transient and sustained features showed similar decay functions with increasing lead intervals. Blink augmentation was found at longer lead intervals early but not late in a session, and was more evident in women than men. Prestimuli with only transient features were more effective than those with both transient and sustained features, showing that sustained stimulus energy at the time of reflex elicitation is not only not necessary for blink augmentation, but also diminishes it.
\end{abstract}

The amplitude of reflexes like the blink reflex in humans and the startle reaction in rats can be modified by brief low-intensity stimuli that occur just prior to the reflexeliciting stimulus (ES). Both inhibition and augmentation of the reflex have been reported. Inhibition is the most common outcome with brief prestimuli presented at stimulus onset asynchronies (SOAs) relative to the ES of about 20 msec to 1-2 sec (Hoffman \& Ison, 1980, 1992), whereas augmentation has been reported with sustained prestimuli presented at longer SOAs with stimulation present at the time of reflex elicitation (e.g., Filion, Dawson, \& Schell, 1993; Graham, Putnam, \& Leavitt, 1975). The experiments reported here were designed to assess the contribution of transient and sustained features of acoustic prestimuli on both inhibition and augmentation of the amplitude of a subsequently elicited blink reflex in humans.

Hoffman and Wible (1969) found that brief (20-msec) prestimuli inhibited the amplitude of the acoustic startle reaction in rats at SOAs from 100 to $1,600 \mathrm{msec}$ with a return to control reflex amplitude (established by presenting the ES alone) at longer SOAs. Sustained stimuli, which remained on until the ES, gave less inhibition than the brief prestimuli at the shorter SOAs and augmentation at SOAs of $400 \mathrm{msec}$ and longer. They concluded that reflex inhibition and augmentation are two largely independent processes, with prestimulus onset responsible for inhibition and the sustained presence of the prestimulus at the time of the ES responsible for augmenta-

Correspondence should be addressed to G. Hammond, Department of Psychology, The University of Western Australia, Nedlands, WA 6907, Australia (e-mail: geoff@psy.uwa.edu.au). tion. Graham and Murray (1977) echoed both conclusions, the independence of the two processes and the attribution of each process to transient and sustained features of the prestimuli. They reported that at SOAs of 30 to $240 \mathrm{msec}$, brief (20-msec duration) and sustained (which remained on until ES onset) prestimuli inhibited reflex amplitude by about the same amount. Because the presence of sustained stimulation in the prolonged prestimuli made no extra contribution to reflex inhibition relative to that obtained with the brief prestimuli, Graham and Murray concluded that inhibition was due solely to the transient features of the prestimulus. They also found a greater facilitation of blink latency at the longer of their SOAs with sustained prestimuli than with brief prestimuli, leading them to ascribe latency facilitation, and facilitatory reflex processes generally, to sustained stimulus features. They proposed that reflex inhibition is effected by a short-time-constant neural system that is activated by transient features of a prestimulus, whereas reflex augmentation is effected by a long-time-constant neural system that is activated by sustained features of a prestimulus.

Dykman and Ison (1979) reexamined the effect of prestimulus duration (2-, 20-, and 200-msec noise bursts with rapid rise and fall times) on inhibition of the acoustic startle reaction in rats and the blink reflex in humans; the lead interval from the midpoint of the prestimulus to the onset of the ES was $150 \mathrm{msec}$ for all prestimulus durations. In contrast to Graham and Murray (1977), they found that reflex inhibition generally increased with prestimulus duration, and concluded that this sensitivity to sustained stimulation showed its dependence on the activity of a long-time-constant neural system that sums energy over time. Similarly, Blumenthal (1995) found in three ex- 
periments that prestimulus inhibition of blink increased as prestimulus duration increased from 6 to $50 \mathrm{msec}$. Blumenthal concluded, like Graham and Murray, that reflex inhibition is mediated by a neural system that is sensitive to transient stimulus features but that shows at least some temporal summation of stimulus energy.

The first direct study of the effect of transient features of the prestimulus on reflex inhibition was reported by Ison (1978), who found that varying the rise and decay time (5 and $100 \mathrm{msec}$ ) of an acoustic prestimulus whose midpoint was $145 \mathrm{msec}$ before the ES did not affect its inhibition of the startle reaction in rats. Similarly, Blumenthal and Levey (1989) found that varying the rise time (from 0.1 to $20 \mathrm{msec}$ ) of a brief (20-msec duration) prestimulus had no effect on blink inhibition, with all prestimuli giving substantial inhibition at the $150-\mathrm{msec}$ SOA. While it can be argued that the 20 -msec rise time was brief enough for stimulus onset to qualify as an acoustic transient, Blumenthal and Levey's finding, together with that of Ison, add no support to the view that prestimulus inhibition is evoked by transient features of the prestimulus, although Blumenthal and Levey argued that, regardless of rise time, the $20-\mathrm{msec}$ prestimulus itself was a transient event. In their second experiment, Blumenthal and Levey found that varying the rise time (from 0.1 to $150 \mathrm{msec}$ ) of prestimuli that were sustained throughout a $150-$ msec SOA had no effect on blink amplitude, although there was a trend toward augmentation from the prestimuli with long rise times (50 to $150 \mathrm{msec}$ ). Despite finding no inhibition from rapid-onset $(0.1-$ and $20-\mathrm{msec}$ rise times) prestimuli at SOAs appropriate for prestimulus inhibition (100-150 msec), Blumenthal and Levey concluded that reflex inhibition is due to activity in a transientsensitive system. In turn, they took their observation of a trend toward reflex augmentation with continuous prestimuli containing only sustained features as demonstrating that augmentation is due to activity in a system that is sensitive to the steady-state features of a prestimulus.

Less experimental attention has been given to augmentation than inhibition of the blink reflex. Graham et al. (1975) described the time course of reflex modification by sustained and brief (14-msec duration) prestimuli at SOAs of 200 to 2,000 msec. Both prestimuli showed an orderly change from inhibition at the shortest SOA to augmentation at the longest SOA, with augmentation appearing earlier and being more marked with the sustained than the brief prestimuli. Inspection of the trialby-trial data reported by Graham et al. shows reflex augmentation to be present in trial blocks early in the test session and diminished, or absent, in later trial blocks. Similarly, Filion et al. (1993) showed that sustained prestimuli at a 2,000-msec SOA augmented the blink reflex in early but not in late trial blocks. A similar finding was reported by Filion, Dawson, and Schell (1994), with blink augmentation at a 2,000-msec SOA in the first but not the second of two trial blocks in a session. Both experiments also showed greater augmentation from an at- tended than an ignored prestimulus. This latter finding, potentiated augmentation from an attended prestimulus at a 2,000-msec SOA, was replicated in the normal controls tested by Schell, Dawson, Hazlett, and Filion (1995), although they failed to find augmentation from the ignored prestimulus in either of two trial blocks, and reported somewhat more augmentation to the attended prestimulus in the second of the two trial blocks. Jennings, Schell, Filion, and Dawson (1996) also reported blink augmentation with sustained prestimuli at SOAs of $2,000 \mathrm{msec}$ and longer, with greater augmentation from attended prestimuli, but made no mention of withinsession changes. Lipp and Siddle (1998) found prestimulus augmentation of blink at a 2,000-msec SOA that was stable over the testing session, a finding replicated in a second experiment. Lipp, Siddle, and Dall (1998) found that the blink reflex was augmented by acoustic and visual, but not vibrotactile, prestimuli presented at SOAs of 3,500 and 4,500 msec. Other studies, however, have not reported clear augmentation with sustained prestimuli. Ornitz, Guthrie, Kaplan, Lane, and Norman (1986) did not find clear evidence of blink augmentation in adults with sustained prestimuli at a 2,000-msec SOA. Likewise, in three experiments, Lane, Ornitz, and Guthrie (1991) did not find consistent evidence of long-SOA augmentation with sustained prestimuli. Both Ornitz et al. and Lane et al. presented only aggregate across-session data, and it is possible that, as in other studies (Filion et al., 1993, 1994; Graham et al., 1975), augmentation was present early but not late in the testing sessions.

Despite a lack of convincing empirical support, the view that prestimulus inhibition is effected by a shorttime-constant neural system that responds to stimulus transients and that prestimulus augmentation is effected by a long-time-constant neural system that responds to sustained stimulation is widespread in the literature (see, e.g., Anthony, 1985; Blumenthal, 1995; Graham, 1980; Jennings et al., 1996; Lane et al., 1991). The experiments reported here were designed to assess the contribution of transient and sustained features of acoustic prestimuli on reflex amplitude at SOAs appropriate for both inhibition and augmentation of the blink reflex. The transient and sustained acoustic features of the acoustic prestimuli were produced by manipulating rise time and plateau duration. Transient features were introduced by switching sinusoidal signals on with a near-instantaneous rise time and without sustained duration, thereby producing stimuli with click-like perceptual qualities; sustained features were introduced by prolonging the plateau duration of the sinusoids after their onset, thereby producing stimuli that had tonal perceptual qualities as well (see, e.g., Moore, 1997). According to Durrant and Lovrinic (1995), the spectral composition of a tone burst is very similar to that of a continuous tone when its plateau duration is $200 \mathrm{msec}$ or longer and its rise and fall times are 10-25 msec. Following this specification, we produced continuous tonal stimuli without transient features in one 
experiment by shaping the onset of sinusoids over $30 \mathrm{msec}$ and prolonging their durations.

\section{EXPERIMENT 1}

In Experiment 1, we examined the separate contributions of transient and sustained features of an acoustic prestimulus to inhibition of the blink reflex at each of two prestimulus intensities.

\section{Method}

Participants. Participants were 14 male volunteers between 16 and 51 years with a median age of 23 years. Three participants were excluded because they did not show blink-related electromyographic (EMG) activity on at least half of the trials when an ES was presented without a prestimulus.

Apparatus and Procedure. All participants gave informed written consent. They were seated in a comfortable reclining chair in a sound-attenuated room and told that they should relax and look forward with eyes open throughout the testing session. The participants had no task to perform and received binaural auditory stimuli through headphones while their blink responses were recorded. Blink reflexes were elicited by brief $(30-\mathrm{msec})$, intense [102$\mathrm{dB}(\mathrm{A}) \mathrm{SL}$ ] bursts of white noise. The ES was presented alone (to establish control levels of reflex responding) or was preceded by one of three prestimulus types at an SOA of $200 \mathrm{msec}$.

The three prestimulus types were created by controlling the onset and offset of a $2-\mathrm{kHz}$ sine wave by modulating the gated output of a Wavetek function generator with an electronic multiplier using the output of a 12-bit digital-to-analog converter as the multiplying signal. One prestimulus type contained both transient and sustained features $(\mathrm{T}+\mathrm{S})$, one contained only sustained features $(\mathrm{S})$, and one contained only transient features $(\mathrm{T})$. The $\mathrm{T}+\mathrm{S}$ prestimulus had a near-instantaneous rise time, the $\mathrm{S}$ prestimulus was shaped on by a cosine function over $30 \mathrm{msec}$ to eliminate onset transients, and the $\mathrm{T}$ prestimulus had a near-instantaneous rise time followed immediately by a linear $5-\mathrm{msec}$ fall time. The durations of the $\mathrm{T}+\mathrm{S}$ and $S$ prestimuli were set at $500 \mathrm{msec}$. The SOA for the $\mathrm{S}$ prestimulus was $200 \mathrm{msec}$ from the halfway point of its 30 -msec onset ramp (and hence $215 \mathrm{msec}$ from literal prestimulus onset and $185 \mathrm{msec}$ from reaching full power). In contrast to the $\mathrm{T}+\mathrm{S}$ and $\mathrm{S}$ prestimulus types, the perceptual quality of the T prestimulus was that of a click and not that of a tone. The three types of prestimuli were presented at two intensities, $75 \mathrm{~dB}(\mathrm{~A}) \mathrm{SL}$ and $61 \mathrm{~dB}(\mathrm{~A}) \mathrm{SL}$, against an ambient background level of $40 \mathrm{~dB}(\mathrm{~A})$ SL measured monaurally with a Brüel and Kjær microphone amplif ier and artificial ear.

EMG activity was recorded with two 6-mm diameter gold-plated electrodes, one placed over the orbicularis oculi muscle just below the lower lid margin, and the other at the lateral canthus. A ground electrode was positioned on the mastoid process behind the ipsilateral ear. The EMG signals were amplif ied with high- and low-pass filters set at $10 \mathrm{~Hz}$ and $1 \mathrm{kHz}$, respectively, and digitized at $4 \mathrm{kHz}$ with a 12-bit analog-to-digital converter. Blinks were scored off-line under visual control, with blink amplitude measured as area in $\mu \mathrm{V} \cdot$ msec. Trials were discarded if they were contaminated with voluntary EMG activity or if there was activity in the $20 \mathrm{msec}$ before the ES; discarded trials accounted for $9 \%$ of all trials.

Seven different trial types were presented-the ES alone (to establish control levels of responding) and the ES preceded by one of the three prestimulus types at either the low or the high intensity. Each condition was randomized in blocks of eight trials, with two control trials in each block. Ten blocks were presented for a total of 80 trials with intertrial intervals randomly selected from a predetermined set varying from 8 to $16 \mathrm{sec}$ with a mean of $12 \mathrm{sec}$. Each participant's median blink amplitude in each condition was ex- pressed as the ratio of the median ES-alone control amplitude. All computations were done with log-transformed ratios, and the results are reported as the geometric means of the median amplitude ratios with $95 \%$ confidence intervals (CIs) calculated using the method described by Loftus and Masson (1994). Geometric means (the arithmetic means of the log-transformed values) are the appropriate averages for values such as ratios, which are multiples of two component quantities.

\section{Results and Discussion}

Figure 1 shows the geometric means of the median amplitude ratios for the three prestimulus types at each of the two intensities. Each of the prestimulus types gave substantial inhibition of the blink reflex (with inhibited reflexes about half the size of control reflexes) at both intensities. Slightly less inhibition was present overall for the $\mathrm{T}(M=0.62,95 \% \mathrm{CI}=0.54-0.71)$ and $\mathrm{S}(M=$ $0.59,95 \% \mathrm{CI}=0.51-0.68)$ prestimulus types than for the $\mathrm{T}+\mathrm{S}$ prestimulus type $(M=0.50,95 \% \mathrm{CI}=0.43-0.57)$. Two observations are noteworthy. First, the observation that the T prestimulus, which contained very little stimulus energy, evoked substantial inhibition shows the potency of onset transients in reflex inhibition, consistent with the position put by Graham and Murray (1977) and Hoffman and Wible (1969). Second, the observation that the $S$ prestimulus evoked substantial inhibition shows that onset transients are not necessary for prestimulus inhibition of the blink reflex. The $\mathrm{T}+\mathrm{S}$ prestimulus type, which contained both transient and sustained features, did evoke somewhat more inhibition than the prestimulus types that contained only one of these stimulus features, but not to an extent that would be expected if the transient and sustained stimulus features made independent and additive contributions to reflex inhibition (see Ison, Zuckerman, \& Russo, 1975). It appears instead that there was partial summation of the inhibitory effects of each stimulus feature. There was little effect of prestimulus intensity, with the means of the two intensities very

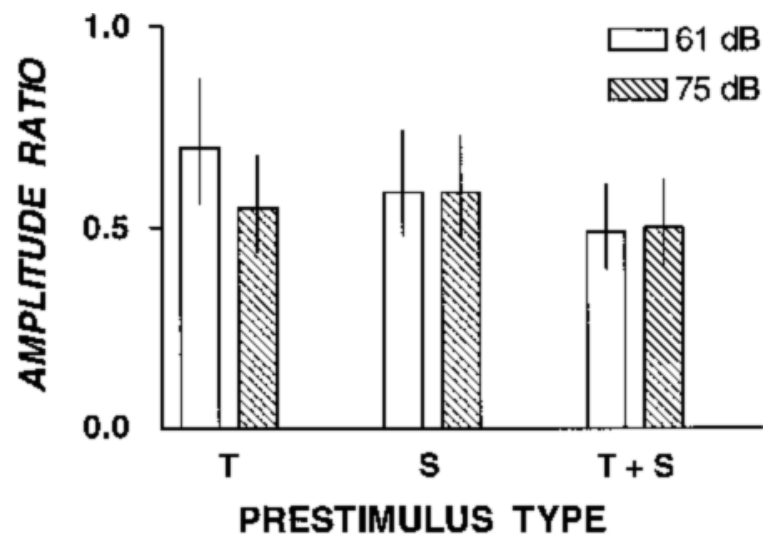

Figure 1. Geometric means of the median amplitude ratios for the transient $(T)$, sustained $(S)$, and transient-and-sustained $(\mathrm{T}+\mathrm{S})$ prestimulus types at the two intensities $(61 \mathrm{~dB}$, open bars; $75 \mathrm{~dB}$, hatched bars) in Experiment 1. Error bars show the $95 \%$ confidence intervals. 
similar for the $\mathrm{S}$ and $\mathrm{T}+\mathrm{S}$ prestimuli; the difference was larger for the $\mathrm{T}$ prestimulus $(0.70$ and 0.55 for the 61 and $75-\mathrm{dB}$ prestimuli respectively) and was present in 8 of the 11 participants.

\section{EXPERIMENT 2}

Experiment 2 was designed to replicate and extend the results of Experiment 1 by examining the time course of reflex modification by prestimuli that differed in their transient and sustained stimulus features. Longer SOAs (400-2,000 msec) were included to examine the contribution of sustained and transient stimulus features to reflex augmentation. With the inclusion of SOA as a variable, two prestimulus types $(\mathrm{T}$ and $\mathrm{T}+\mathrm{S}$ ) were tested in order to obtain an adequate number of observations in each condition without the testing session becoming too long.

\section{Method}

Participants. Participants were 12 male volunteers between 20 and 27 years, with a median age of 22 years. None of the volunteers had participated in the previous experiment.

Apparatus and Procedure. General stimulation and recording procedures were the same as for Experiment 1. The two prestimulus types, $\mathrm{T}+\mathrm{S}$ and $\mathrm{T}$, were generated following the method used in the first experiment and were presented at an intensity of $75 \mathrm{~dB}(\mathrm{~A}) \mathrm{SL}$. Randomized blocks of 12 trials were given, made up of the two prestimulus types presented at each of five SOAs (200, 400, 600, 800, and 2,000 msec) and two ES-alone control trials. As in the first experiment, the $\mathrm{T}+\mathrm{S}$ stimuli were prolonged beyond the SOA, terminating $300 \mathrm{msec}$ after ES onset. Each participant received eight blocks for a total of 96 trials. Intertrial intervals ranged from 8 to $16 \mathrm{sec}$ with a mean of $12 \mathrm{sec}$. Data analysis and recording procedures were the same as those in Experiment 1, and discarded trials accounted for $9 \%$ of all trials. Block-by-block analyses of reflex amplitude were also done to examine within-session changes in reflex modification. In these analyses, the reflex amplitude obtained in each condition in each trial block was expressed as a ratio of the mean amplitude obtained on the two control trials in that block; the resulting eight individual-block ratios were then averaged over the 12 participants.

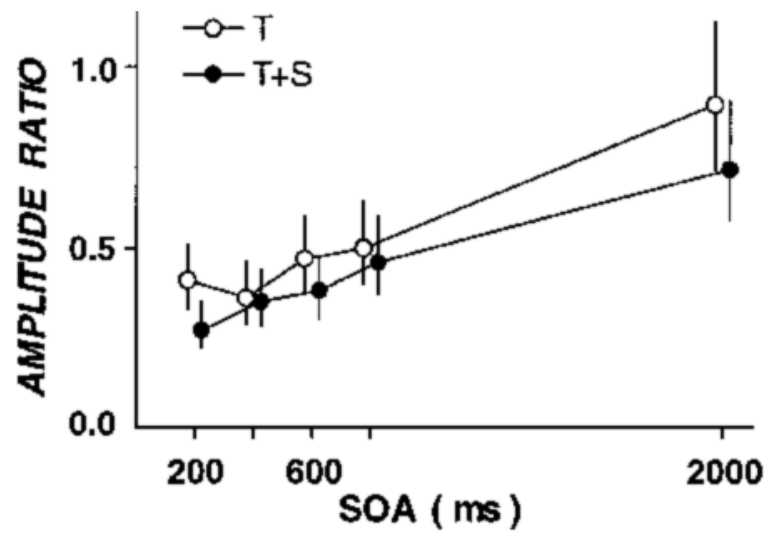

Figure 2. Geometric means of the median amplitude ratios for the transient (open circles) and transient-and-sustained (closed circles) prestimulus types at each stimulus onset asynchrony (SOA) $(200,400,600,800$, and 2,000-msec) in Experiment 2. Error bars show the $95 \%$ confidence intervals. Data points are offset from the abscissa values to show the confidence intervals clearly.

\section{Results and Discussion}

Figure 2 shows geometric means of the median amplitude ratios for the $\mathrm{T}$ and $\mathrm{T}+\mathrm{S}$ prestimuli at each SOA. These results replicate and extend those of Experiment 1 . Both prestimulus types produced substantial inhibition at the 200-msec SOA; inhibition then declined with increasing SOA, with blink amplitudes returning to control levels at the 2,000-msec SOA for the T prestimulus and with some inhibition still present at this SOA for the $\mathrm{T}+\mathrm{S}$ prestimulus. As in Experiment 1, somewhat more inhibition was obtained with the $\mathrm{T}+\mathrm{S}$ than the $\mathrm{T}$ prestimulus at the 200-msec SOA $(M=0.27,95 \% \mathrm{CI}=$ $0.22-0.35$, and $M=0.41,95 \% \mathrm{CI}=0.33-0.51$, respectively), suggesting a partial summation of the inhibitory effects of transient and sustained stimulus features in the $\mathrm{T}+\mathrm{S}$ prestimulus. The decay of inhibition with SOA was nearly linear over the range tested for both prestimuli (adjusted $R^{2}$ values $\geq .96$ ), with similar slopes for each (.98 and 1.0 for the $\mathrm{T}$ and $\mathrm{T}+\mathrm{S}$ prestimuli, respectively). This similarity suggests that transient and sustained features of the prestimuli activate a common inhibitory mechanism rather than separate and functionally opposed systems, as proposed by Graham et al. (1975) and Hoffman and Wible (1969).

Reflex augmentation was not observed in the overall session means of any condition in the present experiment. Figure 3 shows geometric mean amplitude ratios in each trial block for both prestimulus types at the 2,000-msec SOA. Although blink was not augmented relative to control level in any condition, amplitude ratios were not uniform throughout the testing session and approached or exceeded unity in Blocks 3-6 with the T prestimulus and in Block 5 with the $\mathrm{T}+\mathrm{S}$ prestimulus. Single-block means should be interpreted cautiously: Each amplitude ratio is formed from single reflex measurements and so is more subject to error than those based on condition medians; this is reflected in the large CIs around the means. The observed pattern is, however, similar to that reported by Filion et al. (1993, 1994) and Graham et al. (1975) and suggests that prestimulus augmentation is a transitory phenomenon that appears in some experimental settings and may not be present throughout a testing session.

The prestimulus in this experiment might have been too intense to evoke response augmentation. Reijmers and Peeters (1994) showed that reducing prestimulus intensity reduced inhibition of the acoustic startle reaction in rats at short SOAs $(<800 \mathrm{msec})$ and led to the appearance of reflex augmentation at longer SOAs. It is possible that the relatively intense prestimuli used in this experiment $(75 \mathrm{~dB})$ evoked a deep and prolonged phase of reflex inhibition that masked the appearance of reflex augmentation at longer SOAs. This possibility was investigated in the next experiment.

\section{EXPERIMENT 3}

Experiment 3 was designed to assess the effects on the size of the blink reflex of transient and sustained characteristics of acoustic prestimuli presented at each of 


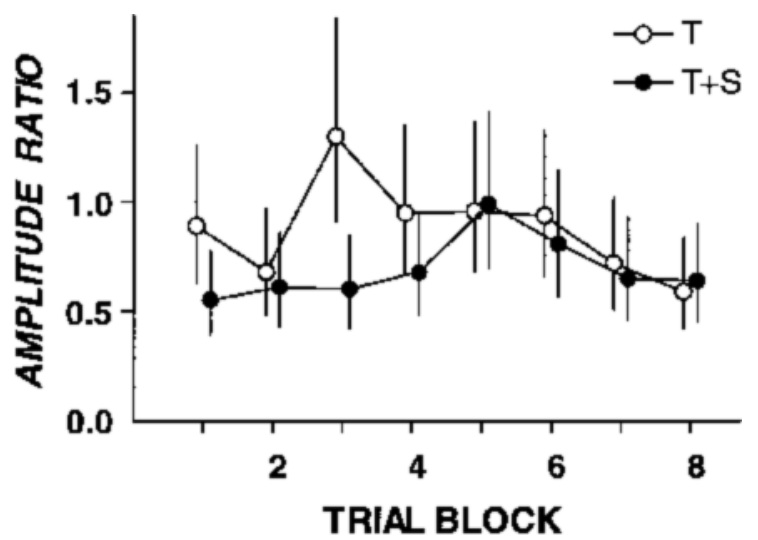

Figure 3. Geometric means of median amplitude ratios for the transient (open circles) and transient-and-sustained (closed circles) prestimulus types at the 2,000 -msec stimulus onset asynchrony in each trial block in Experiment 2. Error bars show the $95 \%$ confidence intervals. Data points are offset from the abscissa values to show the confidence intervals clearly.

three intensities $(50,55$, and $61 \mathrm{~dB})$ at SOAs of 200 and $2,000 \mathrm{msec}$. These intensities were lower than that used in the previous experiment $(75 \mathrm{~dB})$ and were chosen to determine whether low-intensity prestimuli would evoke less inhibition and hence allow the emergence of augmentation at the 2,000-msec SOA.

\section{Method}

Participants. Participants were 6 male volunteers between 22 and 39 years, with a median age of 22 years. Five participants had taken part in one of the two previous experiments.

Apparatus and Procedure. General stimulation and recording procedures were the same as in the previous experiments. The $\mathrm{T}+\mathrm{S}$ and $\mathrm{T}$ prestimuli were presented at three intensities, $50 \mathrm{~dB}(\mathrm{~A}) \mathrm{SL}$, $55 \mathrm{~dB}(\mathrm{~A}) \mathrm{SL}$, and $61 \mathrm{~dB}(\mathrm{~A}) \mathrm{SL}$ at each of two SOAs (200 and $2,000 \mathrm{msec}$ ). The $\mathrm{T}+\mathrm{S}$ prestimuli were $300 \mathrm{msec}$ longer than the SOA. Trials were presented in randomized blocks of 14 trial types made up by the factorial combination of the two prestimulus types, the three prestimulus intensities, and the two SOAs, together with two ES-alone control trials. Seven blocks were given for a total of 98 trials. Intertrial intervals ranged from 8 to $16 \mathrm{sec}$ with a mean of $12 \mathrm{sec}$. Data were analyzed and recorded as in the two previous experiments, and discarded trials accounted for less than $1 \%$ of all trials.

\section{Results and Discussion}

Figure 4 shows the geometric means of the median amplitude ratios for the prestimulus conditions in Experiment 3. Both prestimulus types reduced blink amplitude substantially at the 200-msec SOA. At this SOA the greater inhibition evoked by the $\mathrm{T}+\mathrm{S}$ than the $\mathrm{T}$ prestimulus at the highest stimulus intensity $(61 \mathrm{~dB}$; means and $95 \%$ CIs: $\mathrm{T}+\mathrm{S}=0.39,0.34-0.45, \mathrm{~T}=0.55,0.48-$ $0.64)$ replicates the observations made in the same conditions in Experiment 1. The intensity of the prestimulus had only a small effect on reflex inhibition, and this was different for the two prestimulus types. For the T prestimulus, the most intense prestimulus had a smaller inhibitory effect than the two less intense prestimuli, which each evoked a similar amount of inhibition; for the $\mathrm{T}+\mathrm{S}$ prestimulus, inhibition increased slightly but progressively with intensity.

There was evidence in the overall session means for blink augmentation at the 2,000-msec SOA by the T prestimulus at $55 \mathrm{~dB}$. Blink amplitudes with this prestimulus had returned to near-control amplitudes at the other two intensities (50 and $61 \mathrm{~dB}$ ). The $\mathrm{T}+\mathrm{S}$ prestimulus still inhibited the reflex at the two lower intensities and had little effect at the highest intensity. Despite the appearance of augmentation in one of the conditions, there is no support from these results for the suggestion based on Reijmers \& Peeters's (1994) finding that decreasing prestimulus intensity would unmask reflex augmentation at the longer SOA sufficiently for it to appear in data aggregated over the testing session. Block-by-block geometric means of median amplitude ratios for each prestimulus at the 2,000-msec SOA are shown in Figure 5. Three findings are of interest: First, the amplitude ratios for both prestimuli declined progressively over the session. Second, the amplitude ratios for the $\mathrm{T}$ prestimulus were larger than those of the $\mathrm{T}+\mathrm{S}$ prestimulus in the first half of the session. Third, the T prestimulus (but not the $\mathrm{T}+\mathrm{S}$ prestimulus) augmented the blink in the first trial block. These results are consistent with those of Filion

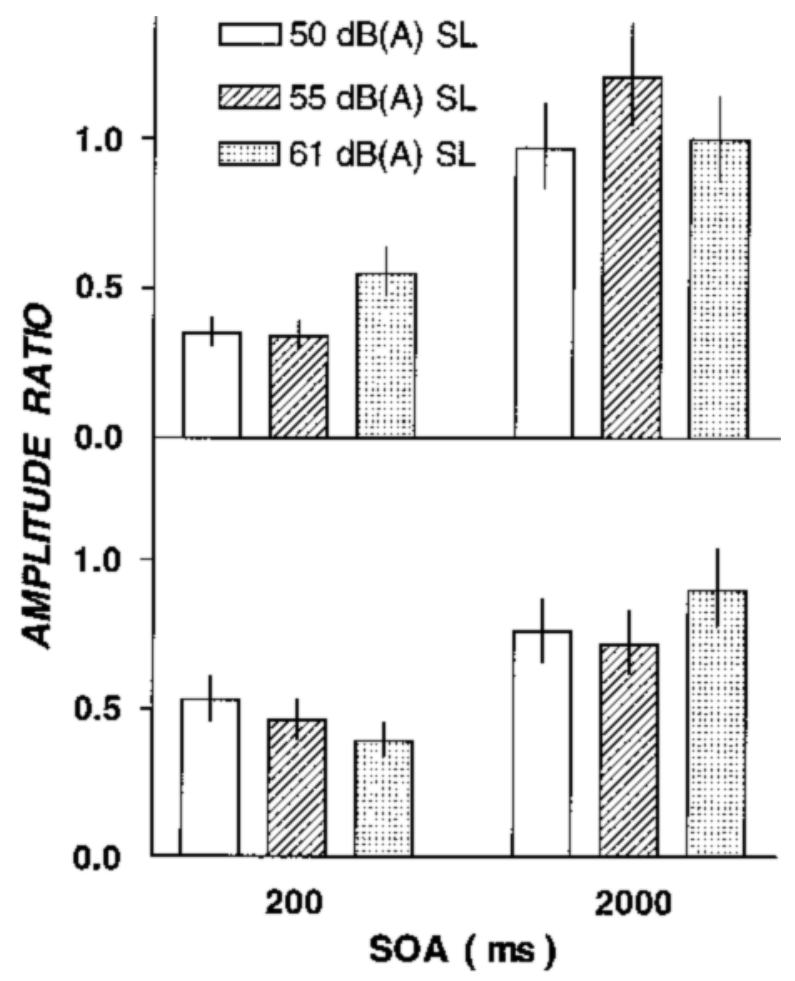

Figure 4. Geometric means of the median amplitude ratios for the transient (top panel) and transient-and-sustained (bottom panel) prestimulus types at each stimulus onset asynchrony (SOA; 200 and 2,000-msec) at each of the three intensities $(50 \mathrm{~dB}$, open bars; $55 \mathrm{~dB}$, hatched bars; $61 \mathrm{~dB}$, stippled bars) in Experiment 3. Error bars show the $95 \%$ confidence intervals. 


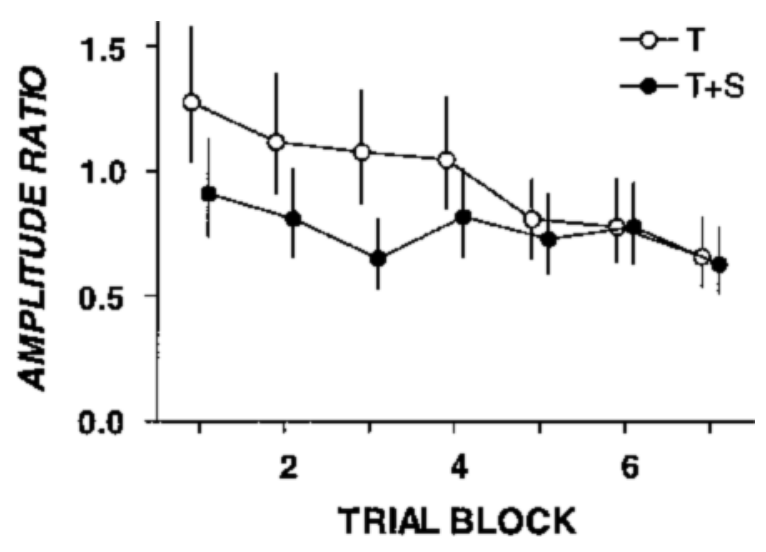

Figure 5. Geometric means of the median amplitude ratios for the transient (open circles) and transient-and-sustained (closed circles) prestimulus types at the $2,000-m s e c$ stimulus onset asynchrony in each trial block in Experiment 3. Error bars show the 95\% confidence intervals. Data points are offset from the abscissa values to show the confidence intervals clearly.

et al. (1993, 1994) and Graham et al. (1975) in that they show that prestimuli at long lead times are more likely to augment the blink reflex early in the testing session. The observation that the $\mathrm{T}$ prestimuli were more likely to augment the blink reflex than the $\mathrm{T}+\mathrm{S}$ prestimuli is contrary to expectation, and shows at least that reflex augmentation is not caused solely by the presence of prolonged prestimuli at the time of reflex elicitation;instead, these data suggest that it is very brief prestimuli with no sustained presence that can augment the blink reflex at long SOAs.

The moderating effect of the logarithmic transformations is seen in a comparison of the arithmetic and geometric means of the amplitude ratios for the 2,000-msec SOA conditions in this experiment. The arithmetic means for each of the six prestimulus conditions at the 2,000msec SOA (Figure 4) were all greater than the corresponding geometric means and were greater than 1 for each intensity of the $\mathrm{T}$ prestimulus at the $2,000-\mathrm{msec}$ SOA $(1.03,1.27$, and 1.05 for the three intensities, respectively; $95 \%$ CIs $= \pm 0.13$ ) and equal to 1 for the highest intensity of the $\mathrm{T}+\mathrm{S}$ prestimulus. Similarly, the arithmetic means were greater than the corresponding geometric means for both prestimuli in each block of the block-by-block analysis (Figure 5), and were greater than 1 for the first four blocks with the $\mathrm{T}$ prestimulus $(1.55,1.19,1.19$, and 1.13 , respectively; $95 \% \mathrm{CI}= \pm 0.16)$ and for the first block with the $\mathrm{T}+\mathrm{S}$ prestimulus (1.35, $95 \% \mathrm{CI}= \pm 0.16$ ).

\section{EXPERIMENT 4}

A review of the papers that have reported the effects of prestimuli at long SOAs suggests that the participants' sex might be important. Filion et al. $(1993,1994)$ and Graham et al. (1975), both of whom reported augmenta- tion of the blink reflex early in the test session, tested samples with $50 \%, 32 \%$, and $44 \%$ female participants, respectively. Schell et al. (1995) and Jennings et al. (1996), both of whom reported augmentation without mention of within-session changes, tested samples with $58 \%$ and $73 \%$ female participants, respectively. Lipp and Siddle (1998), who reported substantial augmentation from acoustic prestimuli throughout the testing session in two separate experiments, tested samples with about $69 \%$ and $61 \%$ females, and Lipp et al. (1998), who reported augmentation with acoustic and visual, but not tactile, prestimuli tested a sample made up of about $75 \%$ female participants (the percentages for the Lipp and Siddle \& Lipp et al. experiments are approximate, since the sex of participants whose data were discarded was not reported). In contrast, Lane et al. (1991) and Ornitz et al. (1986), neither of whom found augmentation despite using stimulus conditions similar to those in studies that had shown augmentation, tested only male participants. Similarly, in Experiments 2 and 3 in the present series, which showed augmentation in only some conditions, only male participants were tested. Females as a group have been reported to show less prestimulus inhibition of the blink reflex than males (Swerdlow et al., 1993), and it may be that they are predisposed to show augmented reflexes with prestimuli presented at long SOAs. The present experiment was designed to investigate the effect of transient and sustained features of an acoustic prestimulus on blink amplitude at brief $(200-\mathrm{msec})$ and longer (1,400- and 2,000-msec) SOAs in males and females.

\section{Method}

Participants. Participants were 10 male and 15 female volunteers, between 17 and 26 years with a median age of 18 years. None of the participants had taken part in any of the previous three experiments.

Apparatus and Procedure. Stimulation and recording procedures were unchanged from the previous three experiments. Participants were presented with the $\mathrm{T}$ and $\mathrm{T}+\mathrm{S}$ prestimuli at an intensity of $61 \mathrm{~dB}(\mathrm{~A}) \mathrm{SL}$ at each of three SOAs $(200,1,400$, and 2,000 msec). Trials were presented in randomized blocks of eight trials made up by the factorial combination of the two prestimulus types and the three SOAs together with two ES-alone control trials. Ten blocks were presented for a total of 80 trials. Intertrial intervals ranged from 8 to $16 \mathrm{sec}$ with a mean of $12 \mathrm{sec}$. Data were analyzed and recorded as in the previous experiments, and discarded trials accounted for less than $4 \%$ of all trials.

\section{Results and Discussion}

Figure 6 shows the geometric means of the median amplitude ratios for each of the prestimulus conditions for males and females separately. Consistent with the report of Swerdlow et al. (1993), the inhibition present at the $200-\mathrm{msec}$ SOA (ignoring prestimulus type) was slightly greater for males than for females (means and 95\% CIs: $0.45,0.37-0.54$, and $0.56,0.48-0.65$ for the males and the females, respectively). The male participants (as in the previous experiments) showed more inhibition to the $\mathrm{T}+\mathrm{S}$ than to the $\mathrm{T}$ prestimulus, but the difference was small (means and 95\% CIs: 0.42, 0.35-0.50, and 0.49, 0.41-0.58 for the $\mathrm{T}+\mathrm{S}$ and the $\mathrm{T}$ prestimuli, respec- 


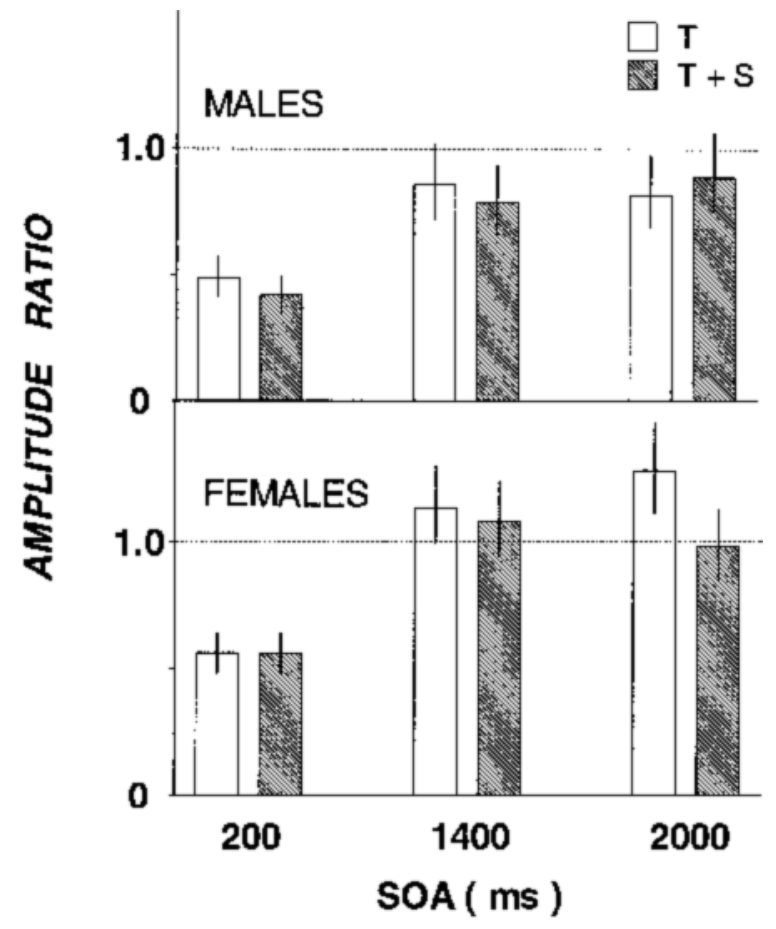

Figure 6. Geometric means of the median amplitude ratios for the transient (open bars) and transient-and-sustained (hatched bars) prestimulus types at each of the three stimulus onset asynchronies (SOAs; 200, 1,400, and $2,000 \mathrm{msec}$ ) in Experiment 4. The top panel shows the data from the male participants and the bottom panel shows the data from the female participants. Error bars show the $95 \%$ confidence intervals.

tively). The females showed no difference between the prestimuli (means and 95\% CIs: $0.56,0.48-0.64$ for both).

The aggregate session scores for the males showed no augmentation with either prestimulus at the longer SOAs, with reflex amplitudes close to but below control levels, a finding similar to that with the $61-\mathrm{dB}$ prestimulus in Experiment 3 . The aggregate session scores for the females as a group showed reflex augmentation at the longer SOAs with the $\mathrm{T}$ but not the $\mathrm{T}+\mathrm{S}$ prestimulus. Figure 7 shows amplitude ratios for both prestimulus types at the 2,000-msec SOA on each of the 10 trial blocks for males and females separately. The males showed a progressive decline in amplitude ratios across the testing session for both prestimulus types. There was evidence of augmentation by the $\mathrm{T}$ prestimulus in the first and third trial blocks, with no systematic effect on blink amplitude later in the session; the $\mathrm{T}+\mathrm{S}$ prestimulus had little effect on blink amplitude in the early trial blocks and inhibited response amplitude in the later blocks (8-10). Although the aggregate scores of the female participants showed clear augmentation by the T prestimulus, the block-byblock amplitude ratios (which are based on single-trial measures) were less conclusive. The within-session decline in amplitude ratios shown by the female participants was not as marked as that shown by the males. The female participants showed larger amplitude ratios for the $T$ than for the $T+S$ prestimulus on 8 of the 10 trial blocks; the mean amplitude ratios were greater than 1 on 8 of the 10 trial blocks for the T prestimulus and on 4 of the 10 trial blocks for $\mathrm{T}+\mathrm{S}$ prestimulus.

Both aggregate and block-by-block analyses of arithmetic means showed the bias toward apparent augmentation. In the aggregate analysis, arithmetic means for both prestimuli at the 1,400- and 2,000-msec SOAs were greater than the corresponding geometric means for both males and females. Although none of the arithmetic means for the male group was greater than 1, which would suggest augmentation, all four arithmetic means were greater than 1 in the female group; at the 1,400-msec SOA, the arithmetic means were 1.18 and 1.22 for the $\mathrm{T}$ and $\mathrm{T}+\mathrm{S}$ prestimuli, respectively, and at the 2,000 - msec SOA, the means were 1.30 and 1.09 , respectively $(95 \% \mathrm{CI}=$ \pm 0.16 ). In the block-by-block analysis for the 2,000 -msec SOA, all arithmetic means for both sexes and both prestimulus types were again greater than the corresponding geometric means. This difference was marked, with in one case the arithmetic mean more than double its corresponding geometric mean. To illustrate the difference, for both sexes and prestimulus types, arithmetic mean ratios of 1.25 or greater outnumbered geometric mean ratios of the same magnitude by more than $2: 1$, and arithmetic

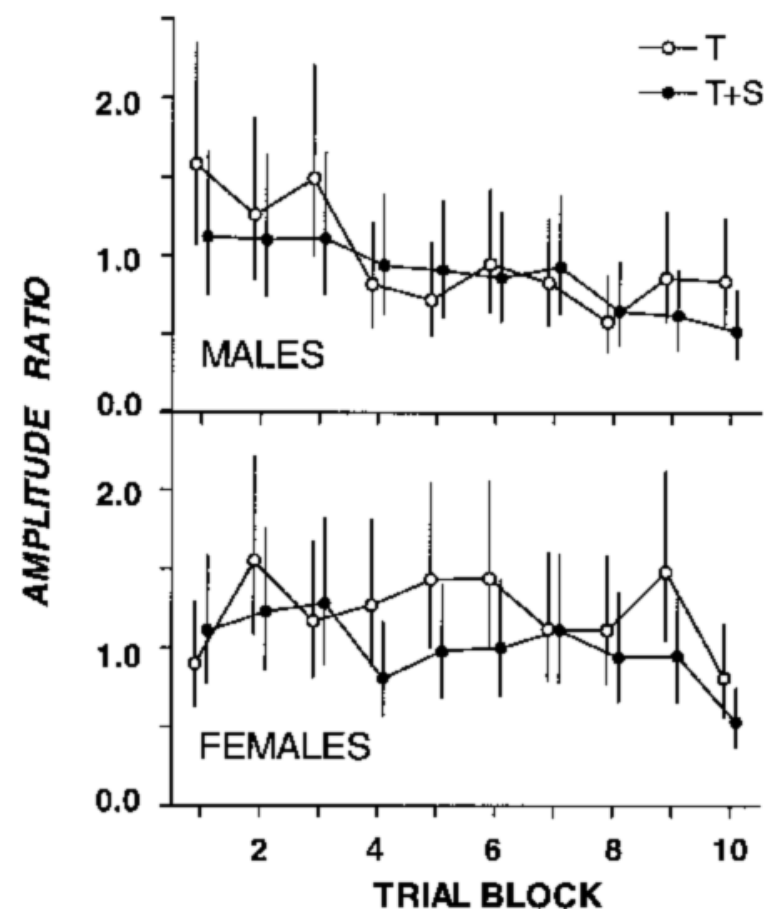

Figure 7. Geometric means of the median amplitude ratios for the transient (open circles) and transient-and-sustained (closed circles) prestimulus types at the 2,000 -msec stimulus onset asynchrony in each trial block for the male participants (top panel) and female participants (bottom panel) in Experiment 4. Error bars show the $95 \%$ confidence intervals. Data points are offset from the abscissa values to show the confidence intervals clearly. 
mean ratios of 1.50 or greater outnumbered geometric mean ratios of the same magnitude by more than $4: 1$. It is clear from these comparisons, and those in the previous experiment, that analyses of ratio scores (or, equivalently, percentages) that take arithmetic means are subject to overestimating both the prevalence and the magnitude of prestimulus-evoked augmentation.

\section{Cross-Experimental Analysis}

The replication or near replication of the $\mathrm{T}$ and $\mathrm{T}+\mathrm{S}$ prestimulus conditions at SOAs of 200 and 2,000 msec in the four experiments allow data from these conditions to be pooled. Figure 8 is a scatterplot of 72 median amplitude ratios obtained with the $\mathrm{T}$ and $\mathrm{T}+\mathrm{S}$ prestimuli at the 200-msec SOA. First, the generality of inhibition in these two conditions is evident, with most data points contained within the lower left quadrant of the plot. Second, with the exception of two outliers, each of which showed an amplitude ratio greater than 2 in one of the prestimulus conditions, a striking covariation of scores is evident ( $r=.65$ with the outliers excluded), with data points falling around a straight line with a slope of 1 . The covariation of scores, in conjunction with reports of high test-retest reliability of prestimulus inhibition (Abel, Waikar, Pedro, Hemsley, \& Geyer, 1998; Schwarzkopf, McCoy, Smith, \& Boutros, 1993), shows prestimulus inhibition to be reproducible across both testing sessions and stimulus conditions. The covariation of inhibitory effect in prestimulus conditions that varied markedly both in temporal structure and total acoustic energy is particularly striking, and shows that both prestimuli, despite their differences, are exerting their inhibitory effects through mechanisms with very similar actions, if not the same mechanism. Figure 9 is a scatterplot of 55 median amplitude ratios obtained with the $\mathrm{T}$ and $\mathrm{T}+\mathrm{S}$ prestimuli presented at the 2,000-msec SOA. Paired data points are shown separately for males (open circles) and females (closed circles). Four points emerge. First, the behavioral

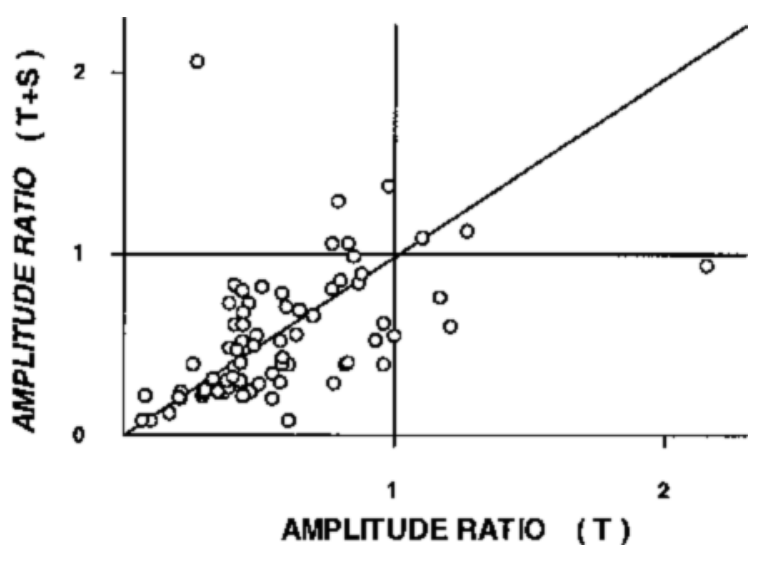

Figure 8. Scatterplot of 72 median amplitude ratios for the $T$ prestimulus (on the abscissa) and $T+S$ prestimulus (on the ordinate) presented at a stimulus onset asynchrony of $200 \mathrm{msec}$ in Experiments 1, 2, 3, and 4.

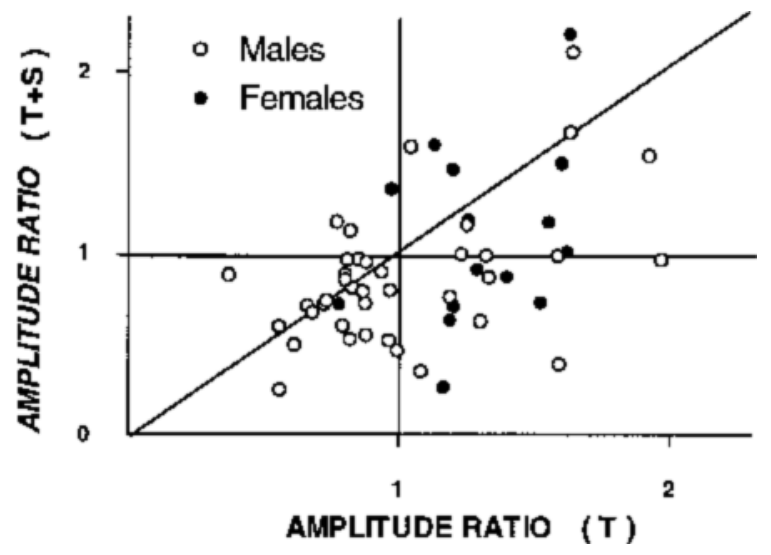

Figure 9. Scatterplot of 55 median amplitude ratios for the $T$ prestimulus (on the abscissa) and $\mathbf{T}+\mathrm{S}$ prestimulus (on the ordinate) presented at a stimulus onset asynchrony of $2,000 \mathrm{msec}$ in Experiments 2, 3, and 4. Male participants are represented by open circles and female participants by filled circles.

effect of both prestimuli at the 2,000-msec SOA is more variable than at the 200-msec SOA, with some individuals showing inhibition (with amplitude ratios less than 1) and others showing augmentation (with amplitude ratios greater than 1). Second, the T prestimulus was more effective than the $\mathrm{T}+\mathrm{S}$ prestimulus in augmenting the reflex: $49 \%$ of the participants had amplitude ratios greater than 1 with the former prestimulus compared with $25 \%$ with the latter. Third, the predisposition of the female participants to augmentation is clear, with 14 of the 15 (93\%) having an amplitude ratio greater than 1 in at least one of the prestimulus conditions compared with 16 of the 40 males $(40 \%)$. Scores from the two prestimulus conditions covaried, but not as strongly as at the $200-\mathrm{msec}$ SOA $(r=.48)$.

\section{GENERAL DISCUSSION}

In the first experiment, an acoustic prestimulus shaped on slowly over $30 \mathrm{msec}$ to avoid onset transients presented $200 \mathrm{msec}$ before a blink-eliciting stimulus inhibited the size of the blink reflex to the same extent as a prestimulus that was switched on abruptly and immediately shaped off rapidly over $5 \mathrm{msec}$ to avoid significant duration. In the first experiment, and in three subsequent experiments, a prestimulus that was switched on abruptly and sustained over a 200-msec SOA inhibited the blink reflex to a somewhat greater extent than the prestimulus that was made up of only the transient acoustic feature. A prestimulus made up of only sustained acoustic energy without transients is able to inhibit the blink reflex, and sustained stimulus energy adds to the inhibitory effectiveness of a transient acoustic prestimulus. These results confirm the idea that acoustic transients are very effective inhibitors of subsequently elicited reflexes but also demonstrate that sustained acoustic energy without transient energy changes is also an effective reflex inhibitor. 
Acoustic transients are effective reflex inhibitors but are not unique in this characteristic. Indeed, Harbin and Berg (1983) reported greater inhibition with prolonged $(200-\mathrm{msec})$ than with brief $(20-\mathrm{msec})$ prestimulation. There is nothing in the present data to encourage the widespread view that brain mechanisms (perhaps within the ascending auditory system) responsive to transient acoustic change are responsible for inhibition of the blink reflex by acoustic prestimuli (e.g., Anthony, 1985; Blumenthal, 1995; Graham, 1980). The results reported here show that it is not fruitful to talk of the neural mechanism of prestimulus inhibition as having either a short or long time constant. Prestimulus inhibition of the blink reflex can be evoked by both transient and sustained stimulus energy, and shows summation of stimulus energy over time (Dykman \& Ison, 1979); furthermore, transient and sustained energy partially summate (Experiments 1-4). It is the case that prestimulus inhibition is mediated either by a neural system that is sensitive to both transient and sustained features of acoustic stimulation, or by distinct neural systems, one sensitive to transient features and the other to sustained. The former possibility is supported by the finding in Experiment 2 of similar time courses of decay of inhibition from the $\mathrm{T}$ and $\mathrm{T}+\mathrm{S}$ prestimuli with increasing SOA and by the crossexperiment finding that the inhibitory effects of the $\mathrm{T}$ and $\mathrm{T}+\mathrm{S}$ prestimuli are correlated and of similar magnitude.

Prestimulus augmentation at relatively long SOAs, unlike prestimulus inhibition at relatively brief SOAs, is not an easily reproduced phenomenon. However, several generalizations can be drawn from the results of the last three experiments. First, amplitude ratios generally decline throughout a testing session, with the result that prestimulus augmentation occurs early, but not late, in a session. Prestimuli that augment the blink reflex early in a session can inhibit the reflex later in the session. As noted, this result is consistent with others reported in the literature and emphasizes the transient nature of prestimulus augmentation. Second, transient acoustic prestimuli without significant duration are more effective than sustained prestimuli without acoustic transients at augmenting the blink reflex. This result is surprising and disconfirms the supposition that reflex augmentation at long SOAs is caused by sustained stimulus energy present at the time of reflex elicitation, and the ancillary hypothesis that reflex augmentation is caused by a modulating neural pathway that is sensitive only to sustained stimulus features. The present experiments did not address the question of whether sustained prestimulation alone is sufficient for reflex augmentation at long SOAs. It is clear, however, that unlike reflex inhibition at short SOAs, where stimuli with sustained and transient acoustic features are more effective than those with only transient features, stimuli with sustained and transient acoustic features are less effective at augmenting the blink at long SOAs than those with only transient features. It appears that adding sustained stimulus energy to a transient acoustic prestimulus diminishes its capacity to augment the blink reflex. Third, blink augmentation is seen more readily in women than in men. This finding has not been reported before, and supports the generalization drawn from the literature on blink augmentation reviewed in the introduction to Experiment 4. The female participants also showed less prestimulus inhibition at the short (200$\mathrm{msec}$ ) SOA and may show, relative to males, a general bias to reflex augmentation rather than inhibition.

It is tempting to argue that prestimulus augmentation is unreliable because it is sensitive to several variables that are often left uncontrolled or unexamined in a particular experiment, such as attention to the prestimulus, the participants' sex, and stage of the testing session. These same variables, however, have also been shown to influence prestimulus inhibition, making the argument unconvincing. Little is known of the nature of reflex augmentation, and it may be a less robust phenomenon than prestimulus inhibition. The method of analysis is also likely to determine whether reflex augmentation appears in a particular data set. The present experiment, and those reported by Ornitz et al. (1986) and Lane et al. (1991), analyzed logarithmic transforms of amplitude ratios and reported geometric means, the appropriate measure of central tendency of ratios that express multiples of two quantities. To illustrate, a quantity (such as an investment) that is doubled and halved does not change, yet the arithmetic mean of the multiples expressed as ratios (2.0 and 0.5) is 1.25, whereas the geometric mean is 1.0. Because the geometric mean cannot exceed the arithmetic mean, it is unsurprising that experiments that have reported geometric means have yielded less evidence of reflex augmentation than those that worked with untransformed ratios (e.g., Lipp et al., 1998) or that took difference scores (e.g., Filion et al., 1993; Graham, 1975).

Nevertheless, the experiments reported here show reflex augmentation with transformed data. These experiments, and others, give no empirical grounds for the supposition that the sustained features of prestimuli are necessary to evoke prestimulus augmentation. In the present experiments, augmentation was most evident with the T prestimulus, and Graham et al. (1975) found clear augmentation with a brief (14-msec) acoustic prestimulus with a near instantaneous rise time at an SOA of 2,000 msec, although their sustained prestimulus did produce more augmentation. Sustained stimulus energy is not necessary for augmentation of the blink reflex; indeed, the widespread conviction that sustained stimulus energy is necessary for prestimulus augmentation has led most to test only sustained prestimuli at long SOAs, seemingly reinforcing the conviction.

\section{REFERENCES}

Abel, K., Waikar, M., Pedro, B., Hemsley, D., \& Geyer, M. (1998). Repeated testing of prepulse inhibition and habituation of the startle reflex: A study in healthy human controls. Journal of Psychopharmacology, 12, 330-337. 
Anthony, B. J. (1985). In the blink of an eye: Implications of reflex modification for information processing. In P. K. Ackles, J. R. Jennings, \& M. G. H. Coles (Eds.), Advances in psychophysiology (Vol. 1, pp. 167-218). Greenwich, CT: JAI.

Blumenthal, T. D. (1995). Prepulse inhibition of the startle eyeblink as an indicator of temporal summation. Perception \& Psychophysics, 57, 487-494.

Blumenthal, T. D., \& Levey, B. J. (1989). Prepulse rise time and startle reflex modification: Different effects for discrete and continuous prepulses. Psychophysiology, 26, 158-165.

Durrant, J. D., \& Lovrinic, J. H. (1995). Bases of hearing science (3rd ed.). Baltimore: Williams \& Wilkins.

Dy Kman, B. M., \& Ison, J. R. (1979). Temporal integration of acoustic stimulation obtained in reflex inhibition in rats and humans. Journal of Comparative \& Physiological Psychology, 93, 939-945.

Filion, D. L., Dawson, M. E., \& Schell, A. M. (1993). Modification of the acoustic startle-reflex eyeblink: A tool for investigating early and late attentional processes. Biological Psychology, 35, 185-200.

Filion, D. L., Dawson, M. E., \& Schell, A. M. (1994). Probing the orienting response with startle modification and secondary reaction time. Psychophysiology, 31, 68-78.

Graham, F. K. (1975). The more or less startling effects of weak prestimulation. Psychophysiology, 12, 238-248.

Graham, F. K. (1980). Control of reflex blink excitability. In R. F. Thompson, L. H. Hicks, \& V. B. Shuyrkov (Eds.), Neural mechanisms of goal-directed behavior and learning (pp. 511-519). New York: Academic Press.

Graham, F. K., \& Murray, G. M. (1977). Discordant effects of weak prestimulation on magnitude and latency of the reflex blink. Physiological Psychology, 5, 108-114.

Graham, F. K., Putnam, L. E., \& Leavitt, L. A. (1975). Leadstimulation effects on human cardiac orienting and blink reflexes. Journal of Experimental Psychology: Human Perception \& Performance, 1, 161-169.

HARBIN, T. J., \& BERG, W. K. (1983). The effects of age and prestimulus duration upon reflex inhibition. Psychophysiology, 20, 603-610.

Hoffman, H. S., \& Ison, J. R. (1980). Reflex modification in the domain of startle: I. Some empirical findings and their implications for how the nervous system processes sensory input. Psychological Review, 87, 175-189.

Hoffman, H. S., \& Ison, J. R. (1992). Reflex modification and the analysis of sensory processing in developmental and comparative research. In B. A. Campbell, H. Hayne, \& R. Richardson (Eds.), Attention and information processing in infants and adults (pp. 83111). Hillsdale, NJ: Erlbaum.
Hoffman, H. S., \& Wible, B. L. (1969). Temporal parameters in startle facilitation by steady background signals. Journal of the Acoustical Society of America, 45, 7-12.

Ison, J. R. (1978). Reflex inhibition and reflex elicitation by acoustic stimuli differing in abruptness of onset and peak intensity. Animal Learning \& Behavior, 6, 106-110.

Ison, J. R., Zuckerman, M., \& Russo, J. M. (1975). Combination rules for inhibitory stimuli. Journal of Experimental Psychology: Animal Behavior Processes, 1, 318-325.

Jennings, P. D., Schell, A. M., Filion, D. L., \& Dawson, M. E. (1996). Tracking early and late stages of information processing: Contribution of startle eyeblink reflex modification. Psychophysiology, 33, 148-155.

Lane, S. J., Ornitz, E. M., \& Guthrie, D. (1991). Modulatory influence of continuous tone, tone offset, and tone onset on the human acoustic startle response. Psychophysiology, 5, 579-587.

LiPP, O. V., \& SidDLE, D. A. T. (1998). The effects of prepulse-blink reflex trial repetition and prepulse change on blink reflex modification at short and long lead intervals. Biological Psychology, 47, 45-63.

LipP, O. V., Siddle, D. A. T., \& DAll, P. J. (1998). Effects of stimulus modality and task condition on blink startle modification and on electrodermal responses. Psychophysiology, 35, 452-461.

LofTus, G. R., \& MAsson, M. E. J. (1994). Using confidence intervals in within-subject designs. Psychonomic Bulletin \& Review, 1, 476-490.

Moore, B. C. J. (1997). An introduction to the psychology of hearing (4th ed.). London: Academic Press.

Ornitz, E. M., Guthrie, D., Kaplan, A. R., Lane, S. J., \& Norman, R. J. (1986). Maturation of startle modulation. Psychophysiology, 23, 624-634.

Reijmers, L. G., \& Peeters, B. W. (1994). Acoustic prepulses can facilitate the startle reflex in rats: Discrepancy between rat and human data resolved. Brain Research Bulletin, 35, 337-338.

Schell, A. M, Dawson, M. E., Hazlett, E. A., \& Filion, D. L. (1995). Attentional modulation of startle in psychosis-prone college students. Psychophysiology, 32, 266-273.

Schwarzkopf, S. B., McCoy, L., Smith, D. A., \& Boutros, N. N. (1993). Test-retest reliability of prepulse inhibition of the acoustic startle response. Biological Psychiatry, 34, 896-900.

Swerdlow, N. R., Auerbach, P., Monroe, S. M., Hartston, H., Geyer, M. A., \& BRAFF, D. L. (1993). Men are more inhibited than women by weak prepulses. Biological Psychiatry, 34, 253-260.

(Manuscript received April 16, 1999;

revision accepted for publication April 6, 2000.) 